Vol. XXIII No $2 \quad 2017$

\title{
RESEARCHING THE INFLUENCE OF ONLINE SOCIAL NETWORKS ON THE STUDENTS' COMMUNICATION - 1ST PART
}

\author{
Mircea FUCIU*, Ruxandra LAZEA**, Luigi DUMITRESCU*** \\ *Romanian-German University of Sibiu, Romania \\ **"1 Decembrie 1918" University of Alba Iulia, Romania \\ ***6"Lucian Blaga" University of Sibiu, Romania \\ mirceafuciu@yahoo.com, ruxandra_rdve@yahoo.com, \\ dumitresculuigi@yahoo.com
}

\begin{abstract}
The usage of online social networks (OSN) in the last decade has changed the manner in which the individuals and especially the young people / students communicate with each other. The aim of our research paper, which is a part of a larger study, is to identify the manner in which the online social networks influence the communication process of the students from Sibiu and Alba Counties of Romania. The present marketing research is a quantitative one, based on a questionnaire that provides a clear insight on what are the main OSN used by the students and it shows how or if the students use the OSN to express their feelings and emotions. The research also shows the influence in the communication process between students and teachers, it points out the main reasons for using such a communication tool and activities undertaken by the students on their preferred OSN.
\end{abstract}

Keywords: communication, social media marketing, social networks, students.

\section{Introduction}

In the new age of communication and of the Internet, the way individuals and especially the young generation is using the new information and communication technology have changed the manner in which we keep in contact and socialize, therefore the companies and their managers must act upon these new changes and use theme to the best of their abilities.

The birth of social media tools, of online social networking sites has shifted the focus of communication from using email, blog or website to using platforms like Facebook, LinkedIn, Google + or Instagram. The students are using more and more these tools in their daily communication process, in their relations with the teachers, with the colleagues, friends or family. As a consequence, the usage of these communication platforms changed their communication style.
This paper, which is the first part of a larger research activity aims to is to identify the manner in which the online social networks influence the communication process of the students from Sibiu and Alba Counties of Romania, we are pointing out the main reasons for using social media platforms, the activities undertaken by them.

\section{Literature review}

Before we discuss and identify how the online social networking sites influence the students' communication process, we must understand the concept and development of the social media platforms. This represents the first part of our literature review.

The opinion varies regarding the development of the online social networking sites, but the concept was presented by various authors starting from the general idea of a social network [1] presented by Acatrinei and Nistor, "which are dynamic 
systems that favours the development of relations between individuals by using a created and shared content" in combination with the usage of an ICT component.

In 2007, U.S. authors Boyd and Ellison [4] define social networking sites "as web-based services that allow individuals to (1) construct a public or semi-public profile within a bounded system, (2) articulate a list of other users with whom they share a connection, and (3) view and traverse their list of connections and those made by others within the system".

Other authors like Preece, and MaloneyKrichmar in 2005, [11] Balas in 2006 [2] or Kasavana in 2010 [9] agree that the online social networking sites (or social media platforms) are a communication tool that is aimed to develop online communities based on common hobbies or interests and by which they publicize personal information / photos about them.

As stated before we must also understand the evolution of the online social networking sites in the last decade or more. Boyd and Ellison [4] suggest that the online social networks have developed around 1997, when sixdegrees.com has appeared. Later on in 2002 other social media sites like Friendster, 2003 with LinkedIn, MySpace, 2004 with Flickr and Facebook (Harvard only) came to life.

The greatest development of the online social networks has happened after 2006 (the year when Facebook was launched worldwide). The last decade has seen the rise of different approaches to online social networking sites, mostly designed by the main objective and target group of individuals desired by their creators.

Today the world biggest social media platform is Facebook.com [16] with: " 1.86 billion monthly active users as of December 31, 2016, 1.74 billion mobile monthly active users as of December 31 , 2016, 1.15 billion mobile daily active users on average for December 2016 and 1.23 billion daily active users on average for December 2016".

In today's Romania there are [17], according to Facebrands.ro: "9,6 million users in Romania, $44,44 \%$ of the population, $85,44 \%$ of the Internet users are Facebook users, with $57,54 \%$ of the Facebook users are between 13 and 34 years old, mostly from urban areas".

The second part of our literature review relates to the aspect of social media and it's influence on the students and their communication process. For the time being we can say that there is a fairly strong interest in the effects of social media on young individuals and students,, on their development, and success, as well as on the negative effects of these platform on the youth $[8,14]$.

According to Bright et.al., [5]," social media has changed the nature of communication whether peer-to-peer, business to consumer or business-tobusiness. Social networking sites like Facebook and micro-blogging sites like Twitter have become some of the primary sources of communication for people to find out about people in their network and brands with which they identify". We concur with this point of view and we consider that the usage on online social networking sites or social media as it is more commonly known has shifted manner in which we, or more exactly the online users communicate.

In the last years, new approaches regarding the usage of social media have sparked the interest of scientists from all over the world. There are authors [14] that state that there is a "link between Facebook use and depression among college students....... Some have questioned whether the relationship exists at all". Other authors [10] mention that "the proliferation of social media has instigated a revolution in the communications field, resulting in consumers expecting the brand to interact with them in a medium where the consumer controls every aspect of the conversation: the time-ing, the channel, and the content". At the same time, some issues have arisen from the usage of social media like "social media fatigue". In the opinion of Bright 
et.al., social media fatigue is defined as ' 'social media users' tendency to back away from social media usage when they become overwhelmed with too many sites, too many pieces of content, too many friends and contacts and too much time spent keeping up with these connections" [15].

We can see from the above-mentioned issues that the online social networks are a challenging subject that has created a wide range of discussion and debate. The current paper is aiming, as stated before, to identify how social media sites are influencing the students of Sibiu and Alba Counties from Romania, focused mainly on the changes that occur in the communication process with friends, family colleagues or even faculty staff using platforms like Facebook.com, LinkedIn, Google+ or many others.

Over the last years, there were important studies [12] that tackle the issue of social media in the relation with reference and affiliation groups. In today's communication context, according to Bartow, Condie \& Livingston [3, 6] the social media is starting to challenge the existing preconceptions of school, teachers, students, and learning. Several other authors $[3,7,13]$ underline the fact that the social technologies bring a large number of changes for the teaching establishments in fields related to the educational, ethical or economic sectors.

At the same time, even if social networking sites are not designed to be used in class, the teaching staff is using them to communicate with the student population in order to promote learning opportunities. Helvie-Mason [7] points out that the students use the OSN platforms in order to connect with their teachers for additional information or to keep in touch with them after school. Sturgeon and

Walker [13] "found that those students who add professors as friends appear to be more willing to communicate with them face-toface if they already know them through the use of social network site". Taking into consideration the above-mentioned aspects, we have developed the following marketing research presented next.

\section{Research methodology}

The main aim of our research paper, which is a part of a larger study, is to identify the manner in which the online social networks influence the communication process of the students from Sibiu and Alba Counties of Romania. We have developed a quantitative, direct, selective marketing research based on a questionnaire distributed to the students of the Faculty of Economics from two universities of Alba and Sibiu counties. The sampling method was based on logical reasoning and was based on the availability of the students. The sample size was of 137 students of both counties. The questionnaire and the research objectives that we used were developed by the authors based on their experience in the field, based on previous studies. The questionnaire had 17 questions (dichotomous and multi-hotomous) of which, 6 were closed questions, 11 were based on 5 or 7 step Likert scale. We also identified a clear profile of the respondents based on their age, gender, residence and income. The specific research objectives established and presented in this first part of our research are: $\mathrm{O}_{1}$ - Identification of the main OSN used by the students; $\mathrm{O}_{2}-$ Determining the usage of OSN and if the students express their feelings via OSN; $\mathrm{O}_{3}$ - Knowing the reasons behind the online student - teacher interaction via OSN; $\mathrm{O}_{4}-$ Identifying the main reasons for having a social media account and the main activities undertaken by the students using their preferred social media platform.

\section{Research results}

The research analysis was developed using the IBM SPSS v. 20 program, and following the actual analysis several important results have come to life that relate to the research objectives states before. Regarding the results for the first objective $\left(\mathrm{O}_{1}\right)$ of our research we have asked the students to identify the main 


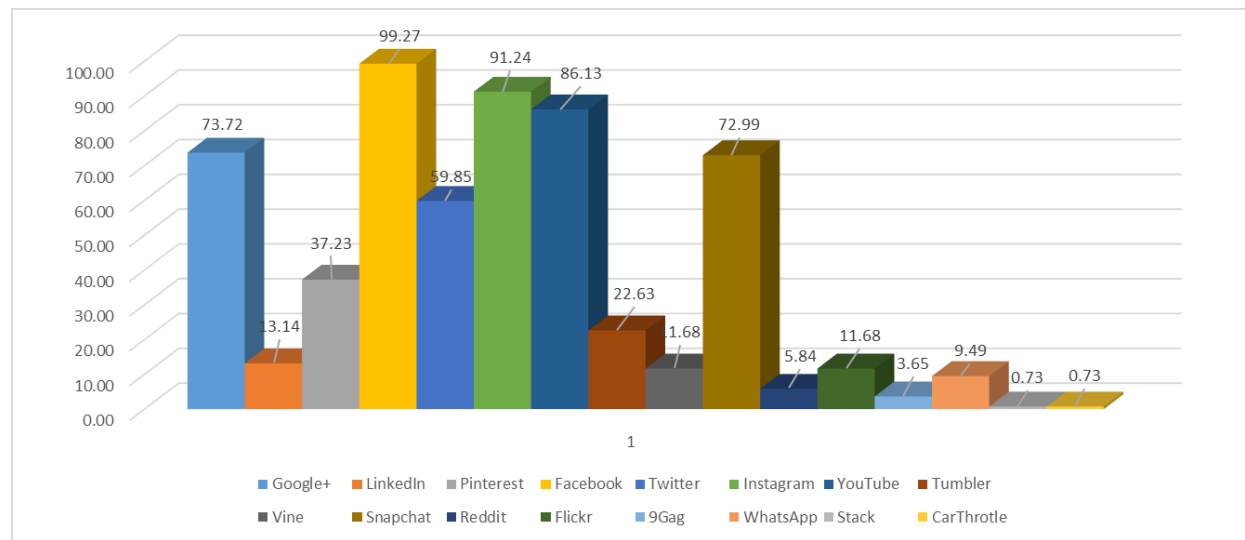

Figure 1: Main online social media platforms known by the respondents

From the results, we can see that for this multiple-choice question, the respondents have identified Facebook the most $(99,27 \%)$, Instagram was known by $91,24 \%$, Twitter (which is more a microblog) is recognised by $86,13 \%$, Google+ was identified by $73,72 \%$ and Snapchat $72,99 \%$. YouTube, which is a video sharing platform is identified by $59.85 \%$. The rest of the responses were below $40 \%$. We should also mention that the students have identified several other platforms like: 9Gag, WhattsApp, Stack and CarThrottle.

We have asked the students to identify the main online social networking platform that the prefer to use. The results show that 77,42\% prefer Facebook.com, 13,71\% prefer the photo based platform Instagram, $8.06 \%$ prefer YouTube and less than $1 \%$ percent prefer Pinterest.

The second objective $\left(\mathrm{O}_{2}\right)$ of our research was to identify the online social networking sites' usage and if they express their feelings via OSN. The most used online social networking platform is Facebook were the students mention that they are mostly permanently connected or connect several times per day. Also with an important usage (connecting several times per day) were YouTube, Snapchat and Google+. The great majority of the respondents do not use or use just for receiving messages or updates on the other social media platforms mentioned.
At the same time, the second objective aimed to identify if the social networks users express their feelings via the platforms. The analysis of the 7 step Likert scale question has shown that the students rarely post their feelings online when they are interacting or are together with friends of family. The registered general score for this question was 3.22, which is just below the average behaviour in this matter. Also we have asked the students to mention how much they use the online social media platforms while they are spending time with friends, family or acquaintances. The results have shown that the students are not using the platforms very much. The score for this question was below the average at 2.49, which continues the idea from the previous presented aspects.

Research objective no. $3\left(\mathrm{O}_{3}\right)$ was established in order to identify the main reasons behind the online student - teacher interaction via OSN. Using a 5 step Likert scale, we have determined that the general score for this question is 3.19 , which shows a more than average interaction between the teaching staff and the students via social media. Regarding the main reasons for developing an online social media based relationship between the parties, the students mentioned that mostly they ask for additional information about different subjects (score = 3.85); to send assignments, reports, projects (score $=3.69)$, to send 
information / rise problems to your advisor (score $=3,15)$. On the average and below the average we had: to announce missing a class (score $=3.01$ ) and to know the teaching staff better (score $=2.27$ ).

The fourth and last objective of the this part of the marketing research was created in order to identify the main reasons for having a social media account and the main activities undertaken by the students using their preferred social media platform. Using the same 5 step Likert scale, we identified that the main activities undertaken by the students on their preferred online social media account are: Plan / organize events (3.96); I play games (3.86); I present myself I my activity (3.72); I look for new friends (3.62); Comment on friends activities (3.27). The rest of the reasons listed by the responded were below the average level of 3. Regarding the main reasons for having an online social network account, the students that took part in our study have shown that the most important reason: $I$ want to communicate with family / friends / acquaintances (4.09); Restart a connection with old friends/ family or acquaintances (3.83); To raise may self-esteem (3.76); I want to be part of an online group (3.47); I want to use the apps or the games (3.44); To not be bored (3.26) and I want to communicate online \& I want to know what is new in my family's life (3.12). The rest of the research items for this objective are below the average level of 3 . As we can see the students have mostly reasons to use the online social networks like communicate with friends and family, as well as other important reasons related to their personal and professional life.

\section{Conclusions}

One of the most changes of the $21^{\text {st }}$ Century society has been generated by the influence and impact of the large scale usage of the online environment and especially of the online social networks.
Today's young generation has greatly adapted and incorporated the usage on online social networking sites and of social media in their everyday life, even though we talk about the professional or the personal one.

With this research paper we aimed to present some results of a larger research developed in the Sibiu and Alba counties in order to identify how the online social networks influence the students' communication. The analysis of the literature review and the research results have shown that a great importance should be given to the matter of the OSN influence on the individuals. As see before, the scientific community has attempted to raise the awareness that these new communication and information platforms affect positively or negatively the users. These elements should be taken into consideration especially in the educational field, because the youth are easy to influence. We have shown during our research that the scientific interest relates to aspects like: interaticon between student and teacher, the concept of social media fatigue, the idea that the students responds better to a teacher that he is conected with etc.

Following the selective marketing research process and the analysis and interpretation of the results, that the students recognise most of the online social media platforms (Facebook, Google+, Pinterest, Instagram) and at the same time they mention that the preferred OSN platform is Facebook, followed by Instagram and YouTube. One element that. We have to mention is the fact, that the students do not differentiate between social networks, micro blogging and video sharing.

Understanding these elements are essential for the implementation of communication strategies and for better targeting the students as online consumers, especially in the context in which we know and understand how they communicate, how they relate with one another, and what motivates them in using these platforms. 


\section{References}

[1] Acatrinei, C., Nistor, F.N., The Romanian perspective upon the social customer and online social networks, Management \& Marketing - challenges for the knowledge society, vol. 7 no. 2, pp. 221 $-236,2012$

[2] Balas, J. (2006), "The social ties that bind”, Computers in Libraries, Vol. 26 No. 2, pp. 39-41.

[3] Bartow, S. M. (2014). Teaching with social media: Disrupting present day public education. Educational Studies: A Journal of the American Educational Studies Association, 50, 36-64. http://dx.doi.org/10.1080/00131946.2013.866954 in Sheldon, P., Understanding students' reasons and gender differences in adding faculty as Facebook friends, Computers and Human Behavior, vol. 53 (2015), pp. 58-62, http://dx.doi.org/10.1016/j.chb.2015.06.043.

[4] Boyd, D.M., Ellison, N., B., Social network sites: a definition, history and scholarship, Journal of Computer Mediated Communication, vol.13, (1), 2007 http://jcmc.indiana.edu/vol13 /issue1/boyd.ellison.html.

[5] Bright, L.F., Kleiser, S.B., Grau,S.L., Too much Facebook? An exploratory examination of social media fatigue, Computers in Human Behavior, vol. 44 (2015), pp. 148-155, http://dx.doi.org/10.1016/j.chb.2014.11.048;

[6] Condie, R., \& Livingston, K. (2007) Blending online learning with traditional approaches: Changing practices. British Journal of Educational Technology, 38, 337-348. in Sheldon, P., Understanding students' reasons and gender differences in adding faculty as Facebook friends, Computers and Human Behavior, vol. 53 (2015), pp. 58-62, http://dx.doi.org/10.1016/j.chb.2015.06.043

[7] Helvie-Mason, L. (2011). Facebook "friending" and faculty-student communication. In C. Wankel (Ed.). Teaching art and science with the new social media, cutting edge technologies in higher education (Vol. 3, pp. 61-87). Emerald Group Publishing Limited.

[8] Junco, R., (2012), The relationship between frequency of Facebook use, participation in Facebook activities, and student engagement, Computer \& Education, vol. 58 (2012), pp. $162-$ 171, doi:10.1016/j.compedu.2011.08.004

[9] Kasavana M. et. al (2010), Online social networking: redefining the human web, Journal of Hospitality and Tourism Technology, vol. 1, no. 1, pp. $68-82$.

[10] Mangold, W. G., \& Faulds, D. J. (2009). Social media: The new hybrid element of the promotion mix. Business Horizons, 52(4), pp. 357-365 in Killian, G., McManus, K., A marketing communications approach for the digital era: Managerial guidelines for social media integration, Business Horizons, 58(2015), pp. 539-549, http://dx.doi.org/10.1016/j.bushor.2015.05.006;

[11] Preece, J. and Maloney-Krichmar, D. (2005), "Online communities: design, theory, and practice", available at: http://jcmc.indiana.edu/vol10/issue4/preece.html;

[12] Sheldon, P., Understanding students' reasons and gender differences in adding faculty as Facebook friends, Computers and Human Behavior, vol. 53 (2015), pp. 58-62, http://dx.doi.org/10.1016/j.chb.2015.06.043;

[13] Sturgeon, C. M., \& Walker, C. (2009). Faculty on Facebook: Confirm or deny. Paper presented at the Annual Instructional Technology Conference, Murfreesboro, TN in Sheldon, P., Understanding students' reasons and gender differences in adding faculty as Facebook friends, Computers and Human Behavior, vol. 53 (2015), pp. 58-62, http://dx.doi.org/10.1016/j.chb.2015.06.043;

[14] Tandoc, E.C., Ferrucci, P., Duffy, M., (2015), Facebook use, envy, and depression among college students: Is facebooking depressing?, Computers in Human Behavior, vol. 43(2015), pp. 139146, http://dx.doi.org/10.1016/j.chb.2014.10.053

[15] ***Technopedia. (2011). Definition of social media fatigue http://www.techopedia.com/definition/27372/social-media-fatigue in Bright, L.F., Kleiser, S.B., Grau,S.L., Too much Facebook? An exploratory examination of social media fatigue, Computers in Human Behavior, vol. 44 (2015), pp. 148-155, http://dx.doi.org/10.1016/j.chb.2014.11.048;

[16] *** Facebook statistics, https://newsroom.fb.com/company-info/ accessed on April $4^{\text {th }}, 2017$;

[17] *** Demographics for Facebook Romania, http://www.facebrands.ro/demografice.html, accessed on April $4^{\text {th }}, 2017$; 